\title{
Influence of Age, Ethnicity and Sex on Body Composition Thresholds for the Accumulation of Visceral Adipose Tissue in Adults
}

\author{
Rachel Marie Watson ${ }^{1}$, Philip Ray Stanforth ${ }^{1,}$, , Anna Elizabeth Talley², \\ Matthew Alan Stults-Kolehmainen ${ }^{3,4}$ \\ ${ }^{1}$ Department of Kinesiology and Health Education, University of Texas at Austin, Austin, USA \\ ${ }^{2}$ Department of Educational Psychology, University of Texas at Austin, Austin, USA \\ ${ }^{3}$ Bariatric Surgery Program, Yale-New Haven Hospital, New Haven, USA \\ ${ }^{4}$ Department of Biobehavioral Sciences, Teachers College, Columbia University, New York, USA
}

Email address:

r.watson@utexas.edu (R. M. Watson),p.stanforth@austin.utexas.edu (P. R. Stanforth), talley.ae@gmail.com (A. E. Talley), Matthew.Stults-kolehmainen@ynhh.org (M. A. Stults-Kolehmainen)

${ }^{*}$ Corresponding author

\section{To cite this article:}

Rachel Marie Watson, Philip Ray Stanforth, Anna Elizabeth Talley, Matthew Alan Stults-Kolehmainen. Influence of Age, Ethnicity and Sex on Body Composition Thresholds for the Accumulation of Visceral Adipose Tissue in Adults. American Journal of Sports Science. Vol. 7, No. 3, 2019, pp. 111-120. doi: 10.11648/j.ajss.20190703.15

Received: June 26, 2019; Accepted: August 4, 2019; Published: August 23, 2019

\begin{abstract}
The purpose of this study was to investigate the influence of age, ethnicity, and sex on the body fat percentage (BF\%) threshold, the point above which visceral adipose tissue (VAT) increases more rapidly. Participants were 1,756 females and 1,455 males, 18-75 years of age, who had a dual X-ray absorptiometry scan. Using segmented linear regression models for each sex and ethnicity category, the BF\% thresholds were identified. The BF\% thresholds for females were: Asian $29.2 \%$, Black 35.6\%, Hispanic 31.7\%, and White 34.2\%. For males, they were: Asian 25.3\%, Black 23.9\%, Hispanic 24.3\%, and White $22.8 \%$. Post-threshold, the impact of $\mathrm{BF} \%$ was amplified for older females $(\beta=0.28, \mathrm{SE}=0.03, p<.001)$ and males $(\beta$ $=0.81, \mathrm{SE}=0.06, p<.001) . \mathrm{BF} \%$ had a weaker association with VAT mass for Black compared to White females $(\beta=-3.05$, $\mathrm{SE}=1.44, p<.05)$ and Asian compared to White males $(\beta=-11.40, \mathrm{SE}=2.30, p<.001)$. The $\mathrm{BF} \%$ threshold was higher in females and varied more with ethnicity in females. Post-threshold the association of BF\% with VAT differed by age and ethnicity, although the influence of ethnicity was different in females than males.
\end{abstract}

Keywords: Abdominal Obesity, Adiposity, DXA, Obesity

\section{Introduction}

Adult obesity is defined as having a body mass index equal to or greater than $30 \mathrm{~kg} / \mathrm{m}^{2}$ [1]. While excess weight is associated with higher chances of cardiovascular disease, cancer, and stroke, the location and type of excess weight is important [2-4]. Specifically, visceral adipose tissue (VAT), the fat that surrounds internal organs in the abdominal (android) area, is positively correlated with cardiometabolic risk factors such as hypertension, dyslipidemia, and insulin resistance $[5,6]$.

Until recently, the only methods for measuring VAT were computerized topography (CT) scans and magnetic resonance imaging (MRI). Having recently been validated against CT scans and MRI's, dual energy x-ray absorptiometry (DXA) is now considered a valid method for measuring VAT [7-9]. DXA is an attractive method for measuring VAT because of the lower radiation emission, quick measurement, and lower cost compared to CT and MRI.

Recently, using DXA technology, it was shown that VAT does not increase linearly with an increase in total body fat percentage $(\mathrm{BF} \%)$ [10-12]. Instead, a $\mathrm{BF} \%$ threshold was identified above which VAT increases more rapidly. Importantly, both females and males with $\mathrm{BF} \%$ above these thresholds scored higher for cardiometabolic risk factors [11]. 
While these thresholds and cardiometabolic risks were determined with a large sample size of females and males, only Black and White participants were included and no ethnic comparisons were conducted [11]. It is known that at similar $\mathrm{BF} \%$ or BMI, there are ethnic [13-28] and age [16, 20, 21, 2934] differences in VAT. It is unknown whether these factors are associated with variability in the $\mathrm{BF} \%$ threshold for the accumulation of VAT. Therefore, the primary purpose of this study was to investigate the influence of age, ethnicity, and sex on the $\mathrm{BF} \%$ threshold at which VAT increases significantly.

\section{Materials Methods}

\subsection{Subjects}

A convenience sample of 3,211 (1,756 females and 1,455 males) participants, $18-75$ years of age, who had a DXA scan conducted at The Fitness Institute of Texas between 2008-2016, were included in this study (Sample A). Self-selected ethnicities were Asian (18.1\%), Black (6.7\%), Hispanic (19.8\%) and White (55.4\%). A subset of Sample A, all 1,473 (800 females and 673 males) Black and White participants from 18-75 years of age (Sample B), was used to match the age and ethnicity of Bosch, Steinberger, Sinaiko, et al. [11]. This study was approved by the University of Texas at Austin Institutional Review Board and meets the standards of the Declaration of Helsinki. Written consent was obtained from each participant.

\subsection{Body Composition Measurement and Protocol}

Body composition was measured using two different DXA machines (Lunar Prodigy and iDXA, GE Healthcare, Chicago, IL) and analyzed using enCore ${ }^{\mathrm{TM}}$ Software version 15. Participants were asked to not eat or perform vigorous exercise two hours prior to testing, to dress in lightweight clothing, and not to wear anything with metal. Participants' total fat mass, lean mass, bone mass, $\mathrm{BF} \%$, and VAT mass were assessed under a standard positioning protocol [35-37]. Several technicians performed and analyzed the scans. Questionable scans were evaluated for either inclusion or exclusion by one technician. Exclusion criteria included those previously established in this laboratory [36], and the inability to estimate VAT. Height and weight were measured on a portable stadiometer (Perspective Enterprises, PE-AIM-101, Portage, MI) and an electronic scale (SECA, 769 Physician Scale, Hamburg, Germany), respectively, with no shoes.

\subsection{Statistical Analysis}

Demographic and body composition characteristics were compared across ethnicity and sex groups with independent ttests for Sample A. All descriptive analyses were conducted using SPSS.

A set of segmented linear regression models were specified to estimate thresholds at which the relationship between $\mathrm{BF} \%$ and VAT mass potentially changed. This type of piecewise regression model is preferred when the threshold (s) is unknown a priori and a linear relationship is assumed within each segment [38]. Single break-point analyses were carried out using the segmented package in $\mathrm{R}$, which uses an iterative least-squares method to fit a pair of non-continuous linear slopes around an estimated level of $\mathrm{BF} \%$. Initial values for the break points were set at $20 \%$ body fat for all analyses. With Sample A, separate segmented models were estimated for each gender and ethnicity category. With Sample B, separate segmented models were estimated for males and females, thus closely replicating Bosch, Steinberger, Sinaiko, et al. [11].

Age and ethnicity were added as covariates in multiple linear regression models and applied to participants whose $\mathrm{BF} \%$ was above the threshold. Specifically, the two-way interactions between each covariate and $\mathrm{BF} \%$ were estimated to assess whether the impact of body fat on VAT mass was affected in any way by age or ethnicity.

\section{Results}

Descriptive statistics for the full sample of females and males (Sample A) are given in Tables 1 and 2, respectively, along with any significant differences identified by the independent $\mathrm{t}$-tests across ethnicity and sex groups. Among ethnicities, White females and males were significantly older than Asians, Blacks, and Hispanics, while Blacks and Hispanics were significantly older than Asians. There was a significant difference in female weight between all ethnicities with Black $>$ White $>$ Hispanic $>$ Asian. The significant differences in weight for males were Black and White $>$ Hispanic $>$ Asian. BF\% for female Hispanics was significantly higher than Asians and Whites, while BF\% for male Hispanics and Whites was significantly higher than Asians and Blacks. VAT mass was significantly higher in White females than Asians or Blacks and in Hispanic females than Asian females. VAT mass was significantly higher in White males than in all other groups and in Hispanic males than in Asian males.

Table 1. Demographic and body composition values for Sample A females.

\begin{tabular}{|c|c|c|c|c|c|}
\hline Ethnicity & $\operatorname{Asian}(n=296)$ & Black $(n=121)$ & Hispanic $(n=356)$ & White $(n=983)$ & All $(n=1756)$ \\
\hline Age (yrs) & $23.6 \pm 6.8^{\mathrm{b}, \mathrm{c}}$ & $27.1 \pm 10.7^{\mathrm{a}}$ & $26.8 \pm 10.4^{\mathrm{a}}$ & $38.1 \pm 14.0^{\mathrm{a}, \mathrm{b}, \mathrm{c}}$ & $32.6 \pm 13.7$ \\
\hline Height (cm) & $160.9 \pm 6.1^{\mathrm{b}}$ & $165.0 \pm 7.4^{\mathrm{a}, \mathrm{c}}$ & $160.5 \pm 6.0^{\mathrm{b}}$ & $165.3 \pm 6.4^{\mathrm{a}, \mathrm{c}}$ & $163.6 \pm 6.7$ \\
\hline Weight (kg) & $58.9 \pm 11.6^{\mathrm{b}, \mathrm{c}}$ & $75.0 \pm 15.6^{\mathrm{a}, \mathrm{c}}$ & $65.5 \pm 14.2^{\mathrm{a}, \mathrm{b}}$ & $68.3 \pm 12.9^{\mathrm{a}, \mathrm{b}, \mathrm{c}}$ & $66.6 \pm 13.8$ \\
\hline Fat Mass (kg) & $19.2 \pm 7.4^{\mathrm{b}, \mathrm{c}}$ & $25.4 \pm 10.4^{\mathrm{a}}$ & $23.3 \pm 9.4^{\mathrm{a}}$ & $22.9 \pm 9.3^{\mathrm{a}, \mathrm{b}}$ & $22.5 \pm 9.3$ \\
\hline Lean Mass (kg) & $37.5 \pm 5.4^{\mathrm{b}, \mathrm{c}}$ & $46.9 \pm 7.4^{\mathrm{a}, \mathrm{c}}$ & $40.0 \pm 5.9^{\mathrm{a}, \mathrm{b}}$ & $42.9 \pm 5.8^{\mathrm{a}, \mathrm{b}, \mathrm{c}}$ & $41.7 \pm 6.4$ \\
\hline Bone Mass (kg) & $2.2 \pm 0.3^{\mathrm{b}, \mathrm{c}}$ & $2.7 \pm 0.3^{\mathrm{a}, \mathrm{c}}$ & $2.3 \pm 0.3^{\mathrm{a}, \mathrm{b}}$ & $2.4 \pm 0.3^{\mathrm{a}, \mathrm{b}, \mathrm{c}}$ & $2.4 \pm 0.3$ \\
\hline
\end{tabular}

Values are mean $\pm \mathrm{SD} ;{ }^{\mathrm{a}}=$ different than Asian, ${ }^{\mathrm{b}}=$ different than Black, ${ }^{\mathrm{c}}=$ different than Hispanic $(p<.05)$. 
Table 2. Demographic and body composition values for Sample A males.

\begin{tabular}{llllll}
\hline Ethnicity & Asian $(\mathbf{n}=\mathbf{2 8 5})$ & Black $(\mathbf{n}=\mathbf{9 5})$ & Hispanic $(\mathbf{n}=\mathbf{2 7 9})$ & White $(\mathbf{n}=\mathbf{7 9 6})$ & All $(\mathbf{n}=\mathbf{1 4 5 5})$ \\
\hline Age $(\mathrm{yrs})$ & $24.6 \pm 7.8^{\mathrm{b}, \mathrm{c}}$ & $30.0 \pm 10.7^{\mathrm{a}}$ & $28.4 \pm 11.3^{\mathrm{a}}$ & $37.2 \pm 14.1^{\mathrm{a}, \mathrm{b}, \mathrm{c}}$ & $32.5 \pm 13.4$ \\
Height $(\mathrm{cm})$ & $174.4 \pm 6.7^{\mathrm{b}}$ & $178.4 \pm 5.8^{\mathrm{a}, \mathrm{c}}$ & $173.8 \pm 6.7^{\mathrm{b}}$ & $179.0 \pm 7.0^{\mathrm{a}, \mathrm{c}}$ & $177.03 \pm 7.2$ \\
Weight $(\mathrm{kg})$ & $75.0 \pm 11.5^{\mathrm{b}, \mathrm{c}}$ & $90.0 \pm 17.7^{\mathrm{a}, \mathrm{c}}$ & $82.6 \pm 16.4^{\mathrm{a}, \mathrm{b}}$ & $86.7 \pm 15.5^{\mathrm{a}, \mathrm{c}}$ & $83.8 \pm 15.9$ \\
Body Fat $(\%)$ & $21.8 \pm 6.7^{\mathrm{c}}$ & $20.4 \pm 8.2^{\mathrm{c}}$ & $24.3 \pm 7.8^{\mathrm{a}, \mathrm{b}}$ & $23.4 \pm 8.0^{\mathrm{a}, \mathrm{b}}$ & $23.1 \pm 7.8$ \\
Fat Mass (kg) & $16.8 \pm 7.2^{\mathrm{c}}$ & $19.5 \pm 12.0$ & $20.9 \pm 10.6^{\mathrm{a}}$ & $21.1 \pm 10.6^{\mathrm{a}}$ & $20.1 \pm 10.2$ \\
Lean Mass $(\mathrm{kg})$ & $55.2 \pm 7.0^{\mathrm{b}, \mathrm{c}}$ & $66.9 \pm 8.5^{\mathrm{a}, \mathrm{c}}$ & $58.6 \pm 8.3^{\mathrm{a}, \mathrm{b}}$ & $62.4 \pm 8.4^{\mathrm{a}, \mathrm{b}, \mathrm{c}}$ & $60.5 \pm 8.8$ \\
Bone Mass $(\mathrm{kg})$ & $3.0 \pm 0.4^{\mathrm{b}}$ & $3.5 \pm 0.5^{\mathrm{a}, \mathrm{c}}$ & $3.1 \pm 0.4^{\mathrm{b}}$ & $3.3 \pm 0.4^{\mathrm{a}, \mathrm{b}, \mathrm{c}}$ & $3.2 \pm 0.5$ \\
VAT Mass $(\mathrm{g})$ & $370 \pm 447^{\mathrm{c}}$ & $523 \pm 651$ & $696 \pm 778^{\mathrm{a}}$ & $892 \pm 911^{\mathrm{a}, \mathrm{b}, \mathrm{c}}$ & $728.5 \pm 824$ \\
\hline
\end{tabular}

Values are mean $\pm \mathrm{SD} ;{ }^{\mathrm{a}}=$ different than Asian, ${ }^{\mathrm{b}}=$ different than Black, ${ }^{\mathrm{c}}=$ different than Hispanic $(p<.05)$.

Results from the segmented linear regressions fit to each gender*ethnicity subgroup are provided in Figures 1-4 (females) and 5-8 (males). A single-threshold model was estimated for all subgroups except for Asian and Hispanic females. For these two subgroups, the presence of influential points towards the upper range of $\mathrm{BF} \%$ and VAT mass caused the single-threshold models to produce break points that were incongruent with the visual inspection of the scatterplot. Specifically, break points above $40 \%$ body fat were estimated for both Asian and Hispanic females. The estimation of a two-threshold model yielded more visually compatible slopes, in addition to increasing the R-squared values for both subgroups. The BF\% threshold for females were: Asian 29.2\%, Black 35.6\%, Hispanic 31.7\%, and White 34.2\%. For males, the $\mathrm{BF} \%$ thresholds were: Asian 25.3\%, Black 23.9\%, Hispanic 24.3\%, and White $22.8 \%$. Below threshold, the slope was significant among White females $(p<0.05)$ and all male subgroups $(p<0.05)$ except Black $(p=0.06)$.

A visual inspection of the scatterplots in Figures 1-8 showed that, for most gender*ethnicity subgroups, there was more variability in VAT mass among participants above the $\mathrm{BF} \%$ threshold than for those below. In order to attempt to explain this additional variability, age and ethnicity were added as covariates in multiple linear regression models applied to post-threshold participants, for both males and females separately (overall $\mathrm{BF} \%$ threshold in Sample A: males $=23.9 \%$, females $=34.6 \%$ ). Table 3 contains the regression coefficients for the sex-specific multiple regressions. Post-threshold, the impact of $\mathrm{BF} \%$ was amplified for older participants adjusting for ethnicity for both females $(\mathrm{N}=683 ; \beta=0.28, \mathrm{SE}=0.03, p<.001)$ and males $(\mathrm{N}=629 ; \beta=0.81, \mathrm{SE}=0.06, p<.001)$, meaning that the VAT increased at a faster rate for older individuals. Adjusting for age, $\mathrm{BF} \%$ had a significantly lower impact on VAT mass for Black females compared to their White counterparts $(\beta=-3.05, \mathrm{SE}=1.44, p<.05)$ and Asian males compared to their White counterparts $(\beta=-11.40, \mathrm{SE}=2.30$, $p<.001)$, meaning that the VAT increased at a faster rate for White females than Black females and White males than Asian males.

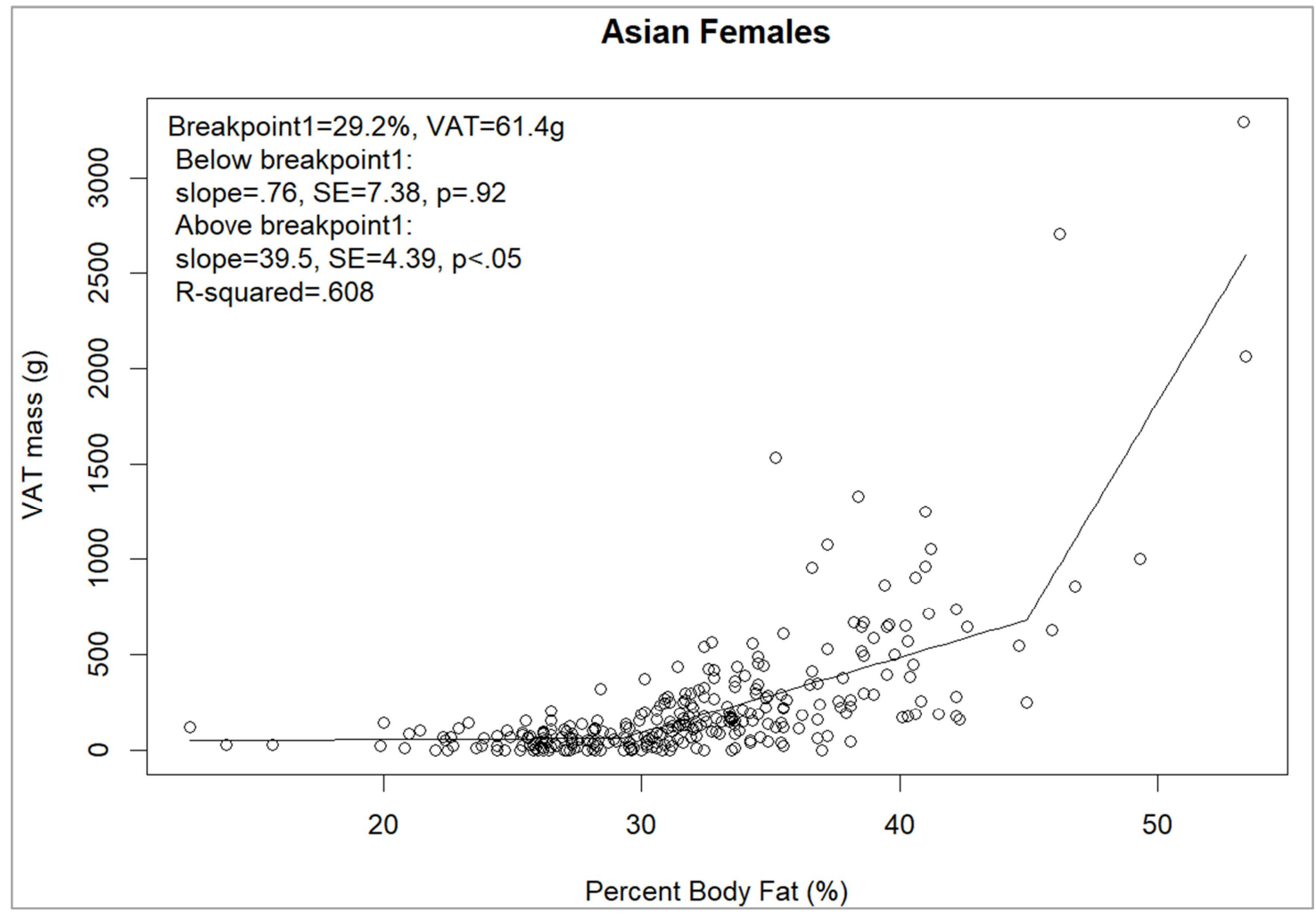

Figure 1. Segmented linear regression on gender*ethnicity in Sample A, Asian females. 


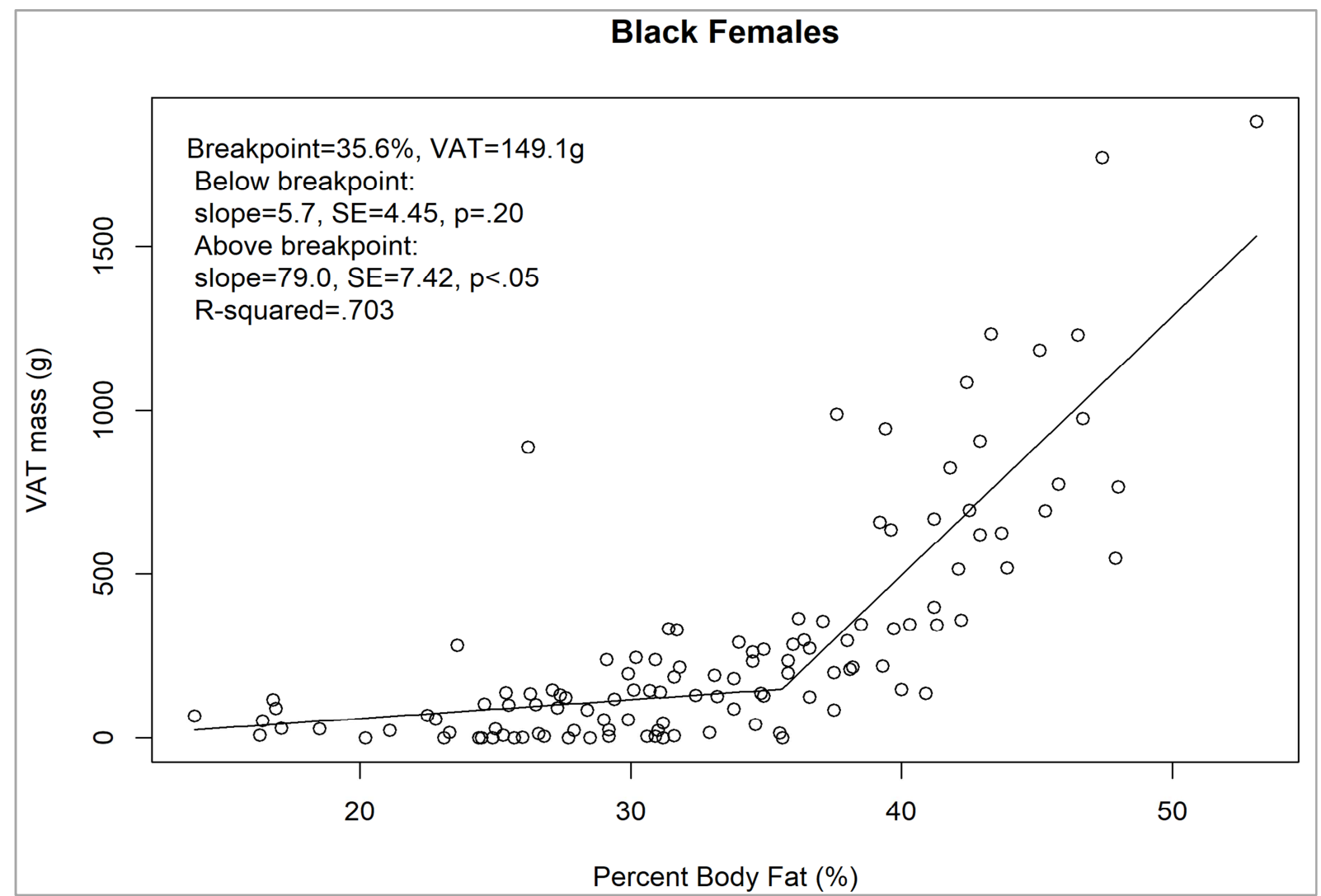

Figure 2. Segmented linear regression on gender*ethnicity in Sample A, Black females.

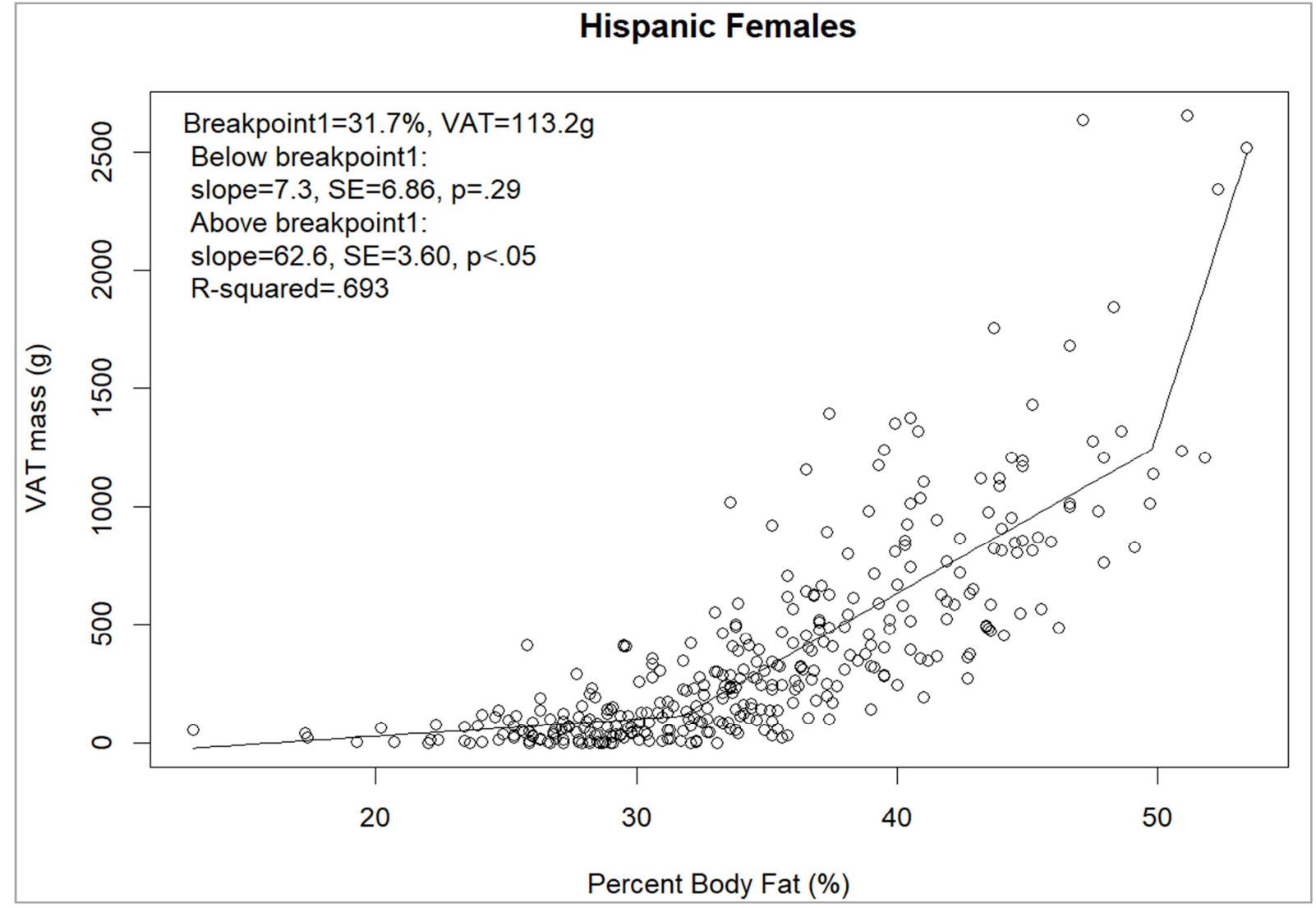

Figure 3. Segmented linear regression on gender*ethnicity in Sample A, Hispanic females. 


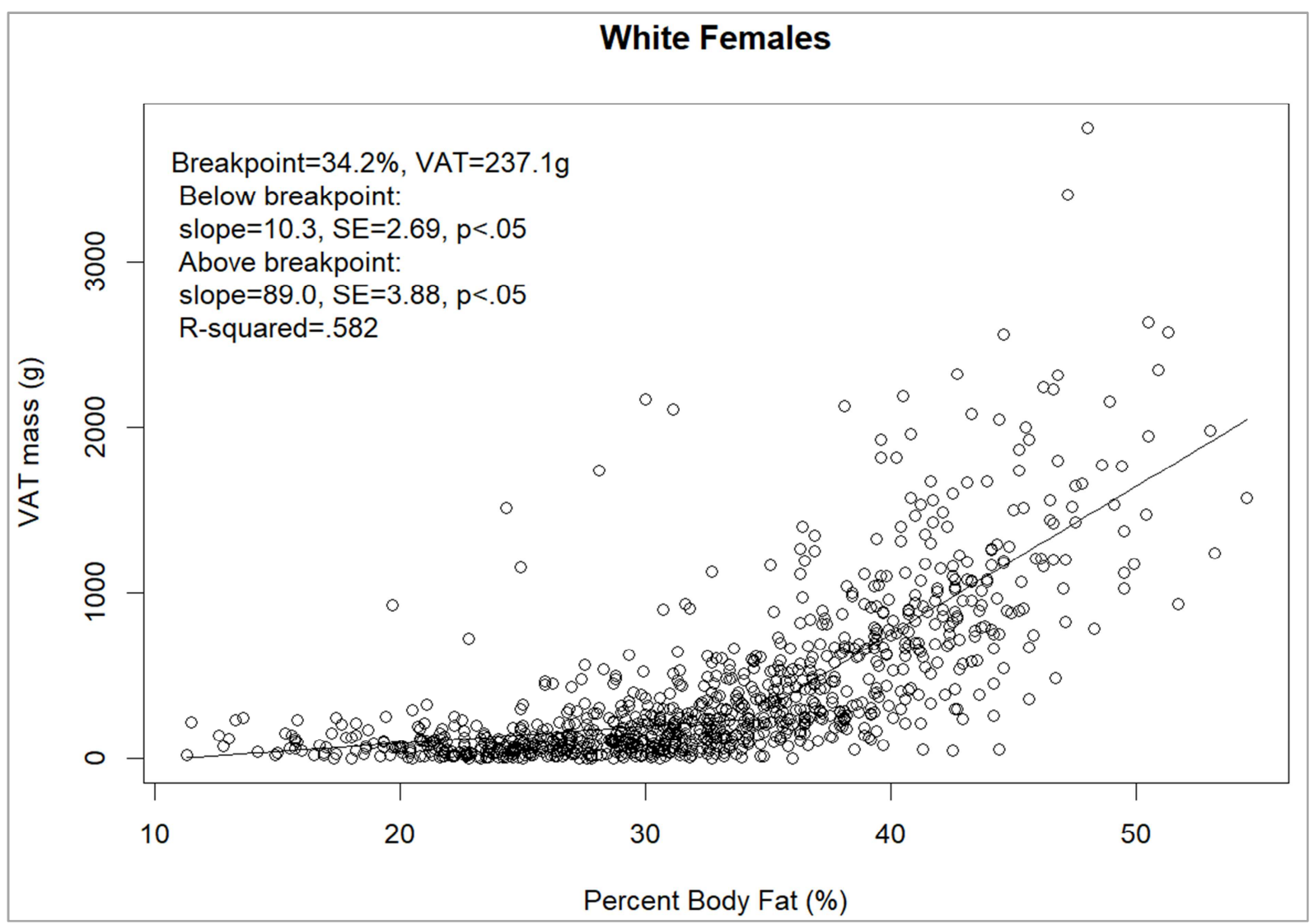

Figure 4. Segmented linear regression on gender*ethnicity in Sample A, white females.

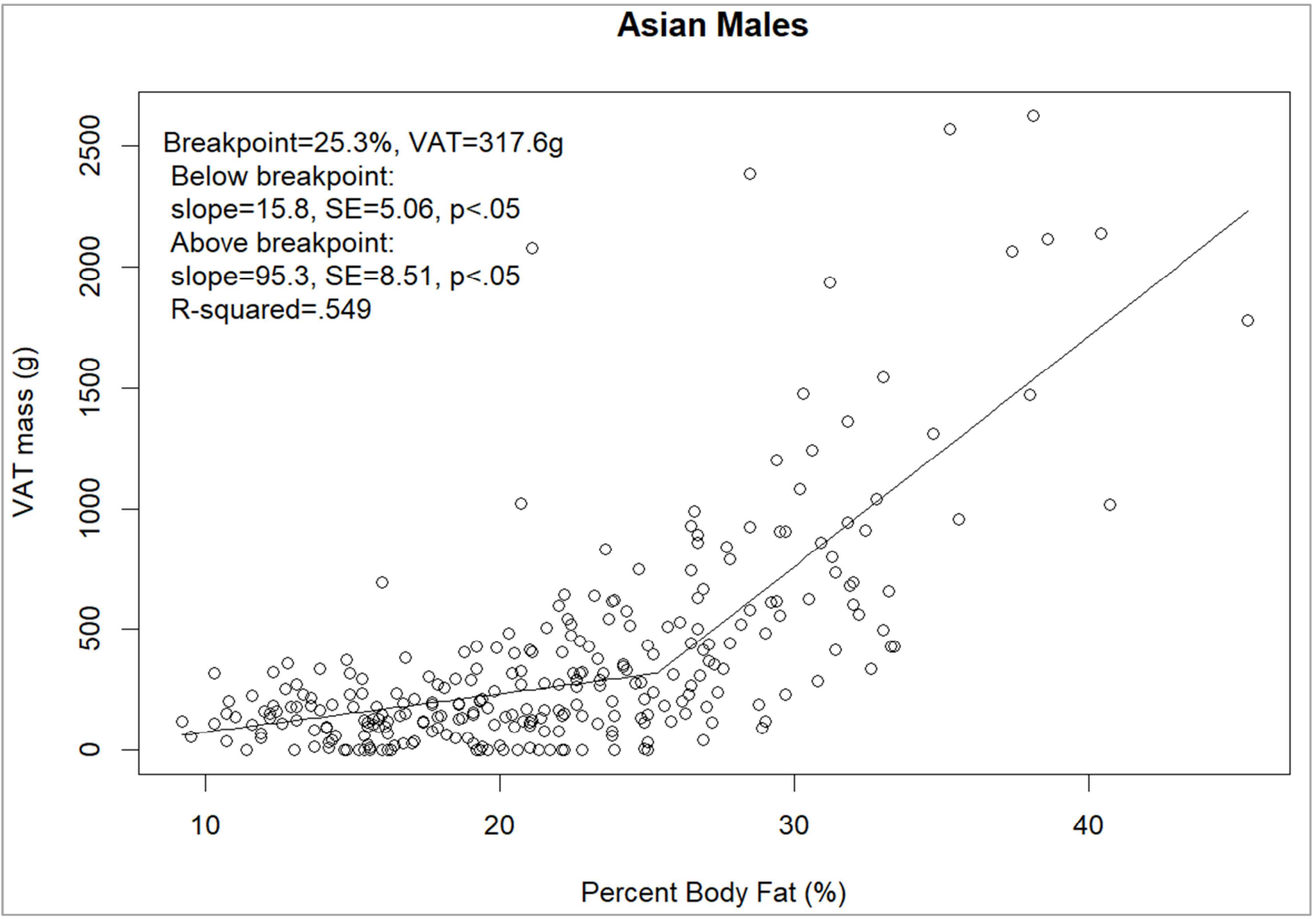

Figure 5. Segmented linear regression on gender*ethnicity in Sample A, Asian males. 


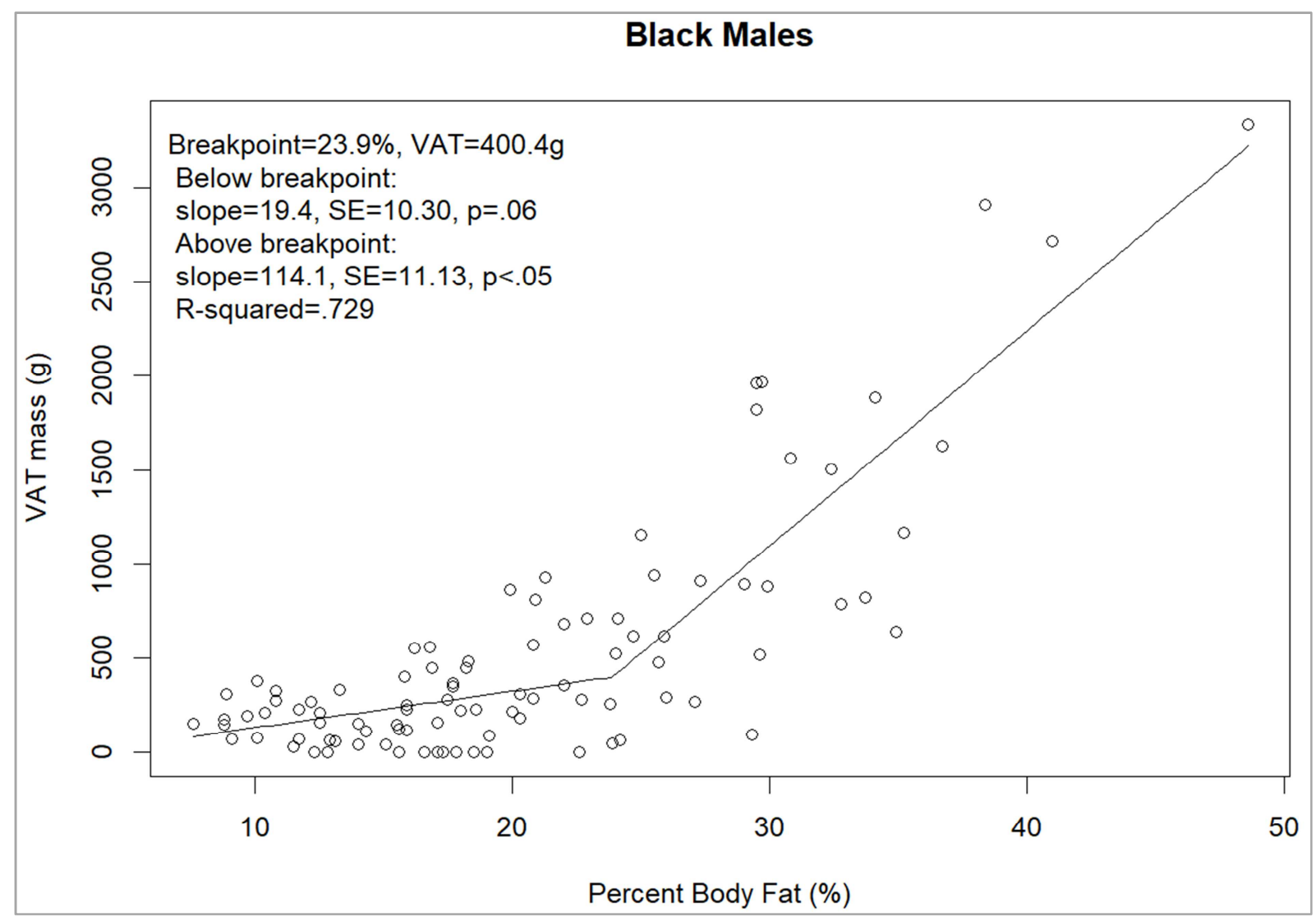

Figure 6. Segmented linear regression on gender*ethnicity in Sample A, black males.

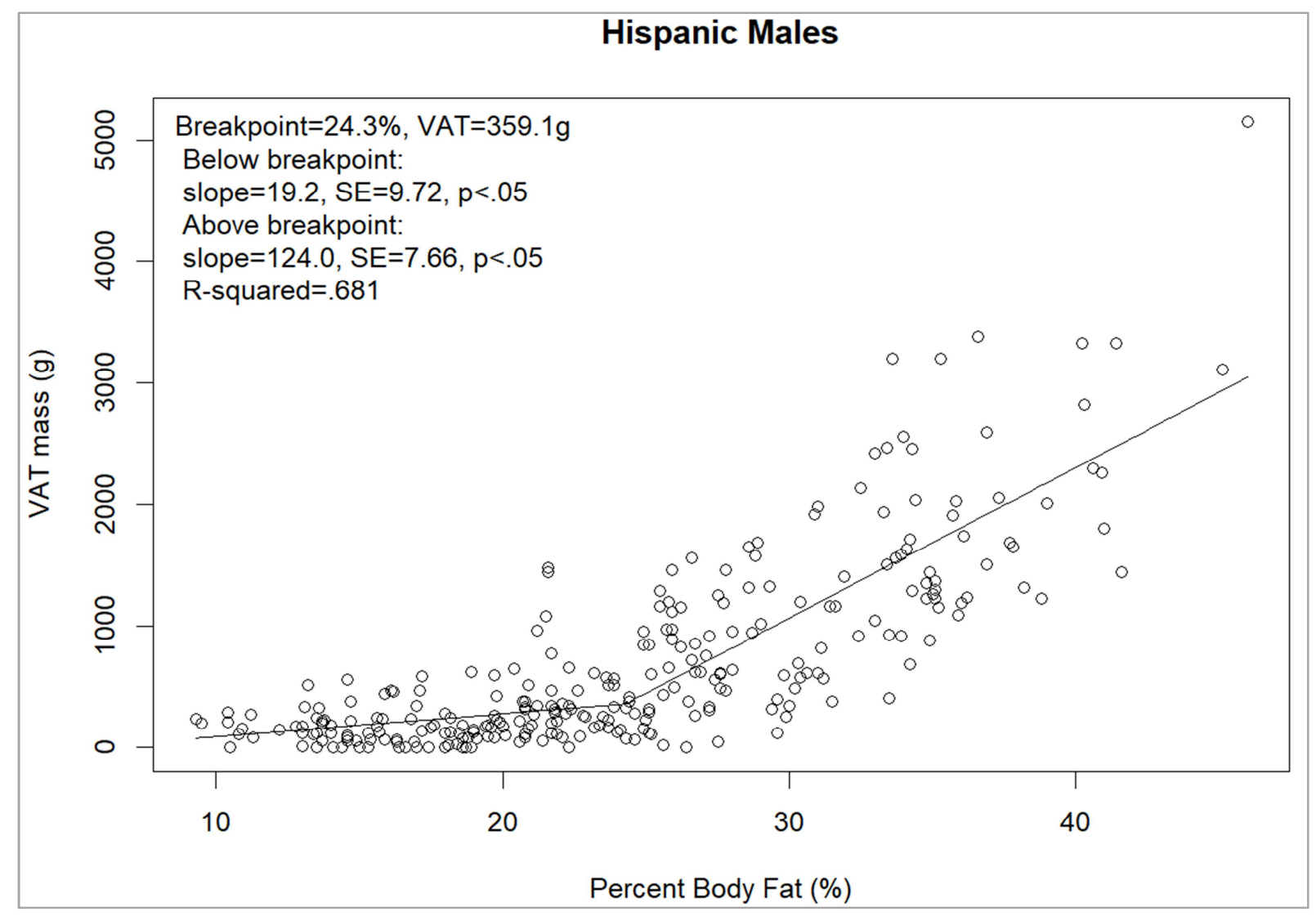

Figure 7. Segmented linear regression on gender*ethnicity in Sample A, Hispanic males. 


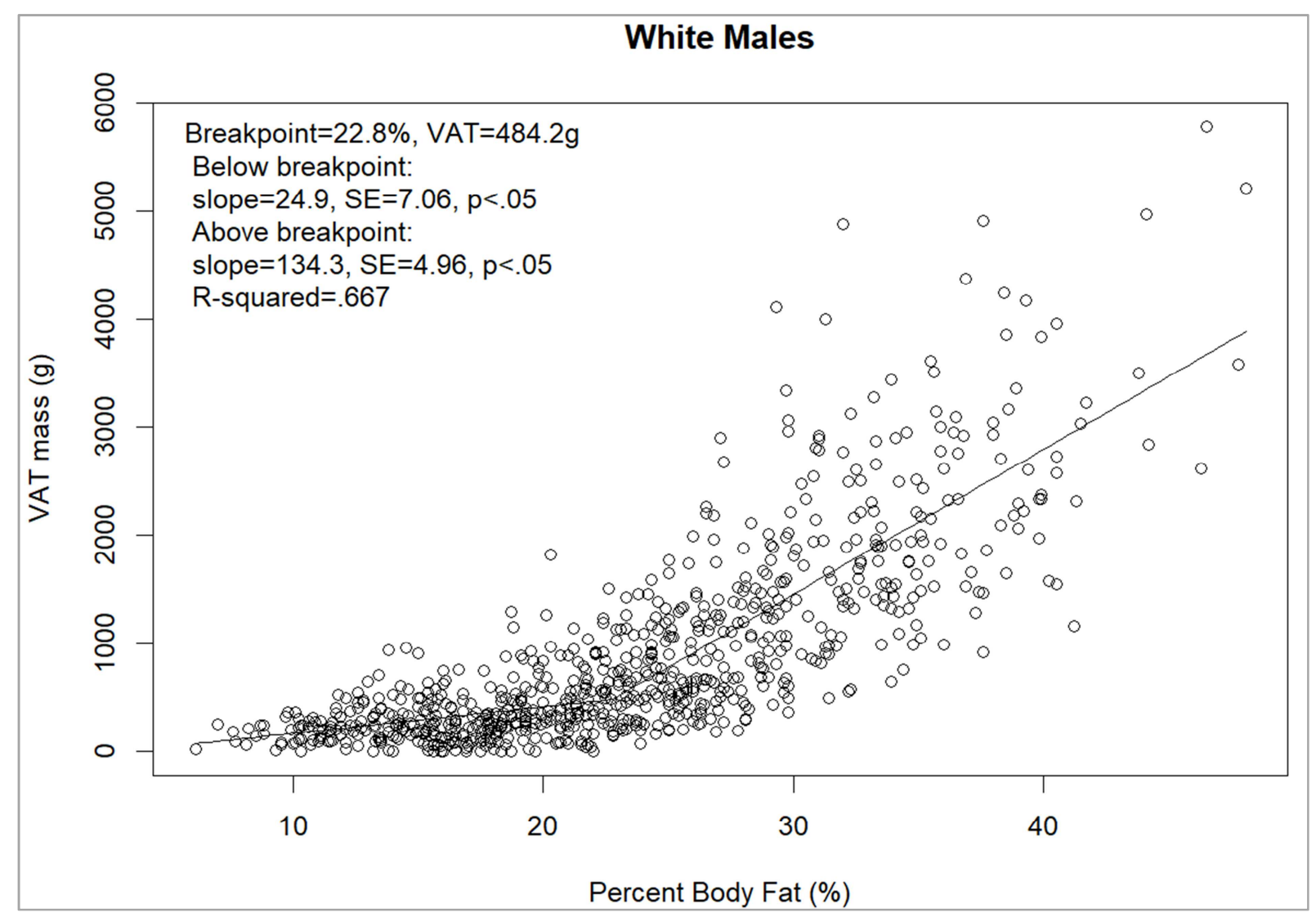

Figure 8. Segmented linear regression on gender*ethnicity in Sample A, White males.

Table 3. Regression coefficients from sex-specific multiple linear regression models predicting VAT mass, post-threshold for Sample A.

\begin{tabular}{lllll}
\hline & Males $>=\mathbf{2 3 . 9 \%}$ body fat & & Females $>=\mathbf{3 4 . 6 \%}$ body fat \\
\cline { 2 - 5 } & $\boldsymbol{\beta}$ & SE & $\boldsymbol{\beta}$ & SE \\
\hline intercept & $-2254.24^{* * *}$ & 142.57 & $-2533.99^{* * *}$ & 145.79 \\
\%BF & $119.38^{* * *}$ & 4.70 & $80.41^{* * *}$ & 3.65 \\
\%BF*age & $0.81^{* * *}$ & 0.06 & $0.28^{* * *}$ & 0.03 \\
\%BF*Black & -5.70 & 3.53 & $-3.05^{*}$ & 1.44 \\
\%BF*Hispanic & -3.76 & 1.92 & 0.71 & 0.97 \\
\%BF*Asian & $-11.40^{* * *}$ & 2.30 & 0.51 & 1.29 \\
\hline
\end{tabular}

Note: Age is centered for post-threshold males and females, separately. The reference category for ethnicity is White. ${ }^{*} p<.05 ;{ }^{* *} p<.01 ; * * * p<.001 . \% \mathrm{BF}=$ percent body fat.

A comparison of demographic and body composition characteristics of the subset of the total number of participants (Sample B) was conducted. The number of both female and male participants in the current study were approximately twice that of Bosch, Steinberger, Sinaiko, et al. [11] and both samples were similarly distributed across age. Both gender groups in the current study had lower mean values for weight, fat mass, $\mathrm{BF} \%$ and VAT mass. Lean mass for males was higher and for females it was lower than in Bosch, Steinberger, Sinaiko, et al. [11]. The BF\% thresholds between the two studies were similar, with female and male values of $36.2 \%$ and $25.8 \%$ in the current study and $38.3 \%$ and $23.4 \%$ in Bosch, Steinberger, Sinaiko, et al. [11]. Unlike the Bosch, Steinberger, Sinaiko, et al. [11] analysis, which found non-significant pre-threshold slopes for both females and males, the initial slopes estimated for Sample B were significantly positive for both gender subgroups. Among females, the pre-threshold slope was estimated as $\beta=9.7$ grams $/ \mathrm{BF} \%(\mathrm{SE}=2.03, p<.05,95 \% \mathrm{CI}=5.72,13.69)$, and the post-threshold slope as $\beta=97.6$ grams $/ \mathrm{BF} \%(\mathrm{SE}=4.51$, $p<.05,95 \% \mathrm{CI}=88.70,106.40)$. This pre-threshold slope is similar to the 10.0 grams $/ \mathrm{BF} \%$, but the post-threshold slope is higher than the 50.6 grams $/ \mathrm{BF} \%$ of Bosch, Steinberger, Sinaiko, et al. [11]. For males, the pre-threshold slope was estimated as $\beta=27.4$ grams $/ \mathrm{BF} \%(\mathrm{SE}=4.22, p<.05,95 \%$ $\mathrm{CI}=19.11,35.68)$, and the post-threshold slope as $\beta=144.7$ grams $/ \mathrm{BF} \%(\mathrm{SE}=6.32, p<.05,95 \% \mathrm{CI}=132.30,157.10)$. Both of these slopes are greater than the pre- and postthreshold slopes of 16.9 grams/BF\% and 77.2 grams/BF\% of Bosch, Steinberger, Sinaiko, et al. [11].

\section{Discussion}

The present study supports previous research [10-12] 
indicating that there is a $\mathrm{BF} \%$ threshold at which VAT increases more rapidly and that this $\mathrm{BF} \%$ threshold is higher in females than males. The novel findings from this study are that $\mathrm{BF} \%$ threshold is affected more by ethnicity in females $(29.2-35.6 \%)$ than in males $(22.8-25.3 \%)$ and that postthreshold threshold slope is affected by age and ethnicity. Post threshold VAT increases more rapidly 1) with age in both men and women, 2) in White females than Black females, and 3) in White males than Asian males.

Females had a higher BF\% threshold than males $(34.6 \%$ vs $23.9 \%$ ) and lower VAT mass at threshold (176 vs $421 \mathrm{~g}$ ). This is in agreement with previous research [11, 12]. When matched for age and ethnicity, the $\mathrm{BF} \%$ thresholds for females $(36.2 \%$ vs $38.3 \%)$ and males $(23.4 \%$ vs $25.8 \%)$, and the pre-threshold slope ( 9.7 vs $10.0 \mathrm{~g} / \mathrm{BF} \%$ ) and VAT mass at threshold (223 vs 250 g) for females were similar between the current study and Bosch, Steinberger, Sinaiko, et al. [11]. However, in males, the pre-threshold slope (27.4 vs 16.9 $\mathrm{g} / \mathrm{BF} \%$ ) and VAT at threshold (558 vs 360 g) were higher in the current study.

While unable to statistically compare the $\mathrm{BF} \%$ threshold among the different ethnicities, there were greater $\mathrm{BF} \%$ threshold differences in females than males. In males the BF\% threshold varied by $2.5 \%$ (White: $22.8 \%$, Black: $23.9 \%$, Hispanic: $24.3 \%$, and Asian: $25.3 \%$.) This agreement and the fact that all of these thresholds are very similar to the previously reported male threshold of 20.1 - 23.4\% [10-12] indicate that the $\mathrm{BF} \%$ threshold is quite uniform in males.

In females, the $\mathrm{BF} \%$ threshold varied by $6.4 \%$ (Asian: 29.2\%, Hispanic: $31.7 \%$, White: $34.2 \%$, and Black: $35.6 \%$.) These values are all lower than the previously reported thresholds of $38.3 \%$ [11] and 39.4\% [12]. Why the BF\% threshold varied more with ethnicity in females than males is unknown. One possibility is that this is a statistical anomaly. The single-threshold statistical model worked for Blacks and Whites, but not Asians and Hispanics. In Asians and Hispanics it produced break points that were incongruent with the visual inspection of the scatterplot and were very high $(>40 \%)$. The estimation of a two-threshold model yielded much better results, but perhaps this skewed the $\mathrm{BF} \%$ threshold downward. Another possibility is that there is greater ethnic variability in $\mathrm{BF} \%$ threshold among females than males. These inconsistencies suggest need for further study.

While not an original purpose of this study, when scatterplots of $\mathrm{BF} \%$ vs VAT were inspected, it was obvious that there was more variability in these plots post $\mathrm{BF} \%$ threshold. This indicates that post BF\% threshold, VAT, and potentially biometabolic risk, increases more rapidly in some individuals than others. Determining the reasons for this greater variability is important, so the post $\mathrm{BF} \%$ threshold values were analyzed to determine whether age and ethnicity could explain some of this increased variability. VAT increased at a faster rate in older females and males. This is consistent with previous studies showing that when controlling for $\mathrm{BF} \%$, older individuals have higher levels of VAT $[16,20,21,29-31,33]$. The only ethnic differences were that VAT increased more rapidly in White than Black females and in White than Asian males. The difference between White and Black females is consistent with most studies [15, $16,19,27,28]$. However, the lack of difference between White and Black males, and White and Hispanic females and males are inconsistent with previous studies which determined that VAT increased faster in White than Black males $[15,16,19,20,27,28]$ and in both White females and males than Hispanics [19]. In addition, the current study showing no difference between the increase in VAT between White and Asian women is consistent with one study comparing White and East Asian women [19], but inconsistent with others showing VAT increased faster in Asians [17], South Asians [22], and Chinese [22], and another showing it increased faster in Whites than in Southeast Asians [19]. Finally, the greater increase in VAT in White than Asian males is inconsistent to a study showing higher VAT in Chinese and South Asians [22]. The existing data is consistent on the effect of age, but inconsistent on the effect of ethnicity. These inconsistencies may be due to measurement, methodological, or population differences and indicate that further studies on the effect of ethnicity are needed.

To put the age changes in perspective, above threshold in females, depending on the age and BF\%, VAT increased by $\sim 10-14 \mathrm{~g} / \mathrm{yr}$ and $\sim 87-97 \mathrm{~g} / \mathrm{BF} \%$. In other words, an increase of 6-9 yrs in age and $1.0 \mathrm{BF} \%$ resulted in a similar increase in VAT. For males, VAT increased by $\sim 20-40 \mathrm{~g} / \mathrm{yr}$ and $\sim 140-170 \mathrm{~g} / \mathrm{BF} \%$. In other words, an increase of $3.5-$ $8.5 \mathrm{yrs}$. in age and $1.0 \mathrm{BF} \%$ resulted in a similar increase in VAT. Above threshold VAT was $106-152$ g (20 - 7\%) higher in White than Black females and $275-570 \mathrm{~g} \mathrm{(25-}$ 9\%) higher in White than Asian males.

A weakness of this study is that no cardiometabolic risk factors were assessed. While previous research [11] has shown an association between the increase in VAT and cardiometabolic risk factors, it is unknown whether this association exists in this more ethnically diverse cohort. Strengths of this study include the sophisticated statistical procedures used and the large sample size; however, both replicated and expanded study samples were primarily White and younger. Future research should explore a sample size evenly distributed by ethnicity. In addition, the study did not break Hispanics and Asians into their country of origin. Differences in VAT has been observed among different Asian subgroups $[17,19,22]$.

\section{Conclusion}

This study confirms the concept of a BF\% threshold for VAT in Black and White females and male and extends it to Asian and Hispanic females and males women. It also confirms and establishes the $\mathrm{BF} \%$ at threshold to a fairly tight window (20-25\%) for males. However, among females the $\mathrm{BF} \%$ threshold is more varied (29-39\%), which warrants further investigation. Across the entire sample, there was more variability in VAT mass above the $\mathrm{BF} \%$ threshold than 
below. This study also confirms that post-threshold, when adjusting for $\mathrm{BF} \%$, VAT increases more rapidly with age and in some ethnicities (i.e., White than Asian males). However, differences in ethnicity are not consistent across different studies. This limits any firm conclusions about the association of ethnicity with VAT thresholds and also warrants further investigation.

\section{Acknowledgements}

Thank you to all of the technicians at the Fitness Institute of Texas who conducted the DXA scans and assisted with the data collection.

\section{References}

[1] Organization WH: Obesity and Overweight Fact Sheet, 2016,

[2] Bhaskaran K, Douglas I, Forbes H, dos-Santos-Silva I, Leon DA, Smeeth L: Body-mass index and risk of 22 specific cancers: a population-based cohort study of $5 \cdot 24$ million UK adults. The Lancet 2014; 384: 755-765.

[3] De Koning L, Merchant AT, Pogue J, Anand SS: Waist circumference and waist-to-hip ratio as predictors of cardiovascular events: meta-regression analysis of prospective studies. Eur Heart J 2007; 28: 850-856.

[4] Yatsuya H, Li Y, Hilawe EH, Ota A, Wang C, Chiang C, Zhang Y, Uemura M, Osako A, Ozaki Y: Global trend in overweight and obesity and its association with cardiovascular disease incidence. Circ J 2014; 78: 2807-2818.

[5] Rothney MP, Catapano AL, Xia J, Wacker WK, Tidone C, Grigore L, Xia Y, Ergun DL: Abdominal visceral fat measurement using dual - energy $\mathrm{X}$ - ray: Association with cardiometabolic risk factors. Obesity 2013; 21: 1798-1802.

[6] Mongraw-Chaffin M, Allison MA, Burke GL, Criqui MH, Matsushita K, Ouyang P, Shah RV, Shay CM, Anderson CAM: CT-Derived Body Fat Distribution and Incident Cardiovascular Disease: The Multi-Ethnic Study of Atherosclerosis. The Journal of Clinical Endocrinology \& Metabolism 2017; 102: 4173-4183.

[7] Choi YJ, Seo YK, Lee EJ, Chung Y-S: Quantification of visceral fat using dual-energy $\mathrm{x}$-ray absorptiometry and its reliability according to the amount of visceral fat in Korean adults. J Clin Densitom 2015; 18: 192-197.

[8] Kaul S, Rothney MP, Peters DM, Wacker WK, Davis CE, Shapiro MD, Ergun DL: Dual - energy X - ray absorptiometry for quantification of visceral fat. Obesity 2012; 20: 1313-1318.

[9] Neeland IJ, Grundy SM, Li X, Adams-Huet B, Vega GL: Comparison of visceral fat mass measurement by dual-X-ray absorptiometry and magnetic resonance imaging in a multiethnic cohort: the Dallas Heart Study. Nutr Diabetes 2016; 6: e221.

[10] Bosch TA, Burruss TP, Weir NL, Fielding KA, Engel BE, Weston TD, Dengel DR: Abdominal body composition differences in NFL football players. The Journal of Strength \& Conditioning Research 2014; 28: 3313-3319.
[11] Bosch TA, Steinberger J, Sinaiko AR, Moran A, Jacobs DR, Kelly AS, Dengel DR: Identification of sex-specific thresholds for accumulation of visceral adipose tissue in adults. Obesity 2015; 23: 375-382.

[12] Bosch TA, Chow L, Dengel DR, Melhorn SJ, Webb M, Yancey D, Callahan H, De Leon MRB, Tyagi V, Schur EA: In adult twins, visceral fat accumulation depends more on exceeding sex-specific adiposity thresholds than on genetics. Metabolism 2015; 64: 991-998.

[13] Beasley LE, Koster A, Newman AB, Javaid MK, Ferrucci L, Kritchevsky SB, Kuller LH, Pahor M, Schaap LA, Visser M, Rubin SM, Goodpaster BH, Harris TB, The Health ABCs: Inflammation and Race and Gender Differences in Computerized Tomography-measured Adipose Depots. Obesity 2009; 17: 1062-1069.

[14] Carroll JF, Chiapa AL, Rodriquez M, Phelps DR, Cardarelli KM, Vishwanatha JK, Bae S, Cardarelli R: Visceral fat, waist circumference, and BMI: impact of race/ethnicity. Obesity 2008; 16: 600-607.

[15] Després J-P, Couillard C, Gagnon J, Bergeron J, Leon AS, Rao DC, Skinner JS, Wilmore JH, Bouchard C: Race, Visceral Adipose Tissue, Plasma Lipids, and Lipoprotein Lipase Activity in Men and Women. The Health, Risk Factors, Exercise Training, and Genetics (HERITAGE) Family Study 2000; 20: 1932-1938.

[16] Katzmarzyk PT, Bray GA, Greenway FL, Johnson WD, Newton RL, Ravussin E, Ryan DH, Smith SR, Bouchard C: Racial differences in abdominal depot-specific adiposity in white and African American adults. The American journal of clinical nutrition 2010; 91: 7-15.

[17] Lesser IA, Yew AC, Mackey DC, Lear SA: A cross-sectional analysis of the association between physical activity and visceral adipose tissue accumulation in a multiethnic cohort. $\mathrm{J}$ Obes 2012; 2012

[18] Lim U, Ernst T, Buchthal SD, Latch M, Albright CL, Wilkens LR, Kolonel LN, Murphy SP, Chang L, Novotny R, Le Marchand L: Asian women have greater abdominal and visceral adiposity than Caucasian women with similar body mass index. Nutrition and Diabetes 2011; 1: e6.

[19] Nazare J-A, Smith JD, Borel A-L, Haffner SM, Balkau B, Ross R, Massien C, Alméras N, Després J-P: Ethnic influences on the relations between abdominal subcutaneous and visceral adiposity, liver fat, and cardiometabolic risk profile: the International Study of Prediction of IntraAbdominal Adiposity and Its Relationship With Cardiometabolic Risk/Intra-Abdominal Adiposity. The American journal of clinical nutrition 2012; 96: 714-726.

[20] Hoffman DJ, Wang Z, Gallagher D, Heymsfield SB: Comparison of visceral adipose tissue mass in adult African Americans and whites. Obes Res 2005; 13: 66-74.

[21] Demerath EW, Sun SS, Rogers N, Lee M, Reed D, Choh AC, Couch W, Czerwinski SA, Chumlea WC, Siervogel RM: Anatomical patterning of visceral adipose tissue: race, sex, and age variation. Obesity 2007; 15: 2984-2993.

[22] Lear SA, Humphries KH, Kohli S, Chockalingam A, Frohlich JJ, Birmingham CL: Visceral adipose tissue accumulation differs according to ethnic background: results of the Multicultural Community Health Assessment Trial (M-CHAT). The American journal of clinical nutrition 2007; 86: 353-359. 
[23] Araneta MRG, Barrett - Connor E: Ethnic differences in visceral adipose tissue and type 2 diabetes: Filipino, African - American, and white women. Obes Res 2005; 13 $1458-1465$

[24] Raji A, Seely EW, Arky RA, Simonson DC: Body fat distribution and insulin resistance in healthy Asian Indians and Caucasians. The Journal of Clinical Endocrinology \& Metabolism 2001; 86: 5366-5371.

[25] Wagenknecht LE, Langefeld CD, Scherzinger AL, Norris JM, Haffner SM, Saad MF, Bergman RN: Insulin sensitivity, insulin secretion, and abdominal fat. Diabetes 2003; 52: 24902496.

[26] Cervantes A, Singh RG, Kim JU, DeSouza SV, Petrov MS: Relationship of Anthropometric Indices to Abdominal Body Composition: A Multi-Ethnic New Zealand Magnetic Resonance Imaging Study. J Clin Med Res 2019; 11: 435446.

[27] Camhi SM, Bray GA, Bouchard C, Greenway FL, Johnson WD, Newton RL, Ravussin E, Ryan DH, Smith SR, Katzmarzyk PT: The Relationship of Waist Circumference and BMI to Visceral, Subcutaneous, and Total Body Fat: Sex and Race Differences. Obesity 2011; 19: 402-408.

[28] Ronn P, Andersen G, Lauritzen T, Christensen D, Aadahl M, Carstensen B, Jorgensen $\mathrm{M}$ : Ethnic differences in anthropometric measures and abdominal fat distribution: A cross-sectional pooled study in inuit, africans and europeans. J Epidemiol Community Health 2017; 71: 536-543.

[29] Lee CG, Fujimoto WY, Brunzell JD, Kahn SE, McNeely MJ, Leonetti DL, Boyko EJ: Intra-abdominal fat accumulation is greatest at younger ages in Japanese-American adults. Diabetes Res Clin Pract 2010; 89: 58-64.

[30] Borkan GA, Hults DE, Gerzof SG, Robbins AH, Silbert CK: Age changes in body composition revealed by computed tomography. J Gerontol 1983; 38: 673-677.
[31] Pascot A, Lemieux S, Lemieux I, Prud'homme D, Tremblay A, Bouchard C, Nadeau A, Couillard C, Tchernof A, Bergeron $\mathrm{J}$ : Age-related increase in visceral adipose tissue and body fat and the metabolic risk profile of premenopausal women. Diabetes Care 1999; 22: 1471-1478.

[32] Hirose H, Takayama M, Iwao Y, Kawabe H: Effects of aging on visceral and subcutaneous fat areas and on homeostasis model assessment of insulin resistance and insulin secretion capacity in a comprehensive health checkup. Journal of Atherosclerosis and Rhrombosis 2015; 22: 207-215.

[33] Amdanee N, Di W, Liu J, Yu J, Sheng Y, Lv S, Chattun MR, Hanmei Q, Liu W, Tang L, Ding G: Age - associated changes of resting energy expenditure, body composition and fat distribution in Chinese Han males. Physiological Reports 2018; 6: e13940.

[34] Szulc P, Duboeuf F, Chapurlat R: Age-Related Changes in Fat Mass and Distribution in Men - the Cross-Sectional STRAMBO Study. J Clin Densitom 2017; 20: 472-479.

[35] Mazess RB, Barden HS, Bisek JP, Hanson J: Dual-energy xray absorptiometry for total-body and regional bone-mineral and soft-tissue composition. The American journal of clinical nutrition 1990; 51: 1106-1112.

[36] Stults-Kolehmainen MA, Stanforth PR, Bartholomew JB: Fat in android, trunk, and peripheral regions varies by ethnicity and race in college aged women. Obesity 2012; 20: 660-665.

[37] Stults-Kolehmainen M, Stanforth P, Bartholomew J, Lu T, Abolt C, Sinha R: DXA estimates of fat in abdominal, trunk and hip regions varies by ethnicity in men. Nutrition \& diabetes 2013; 3: e64.

[38] Muggeo VM: Estimating regression models with unknown break-points. Stat Med 2003; 22: 3055-3071. 